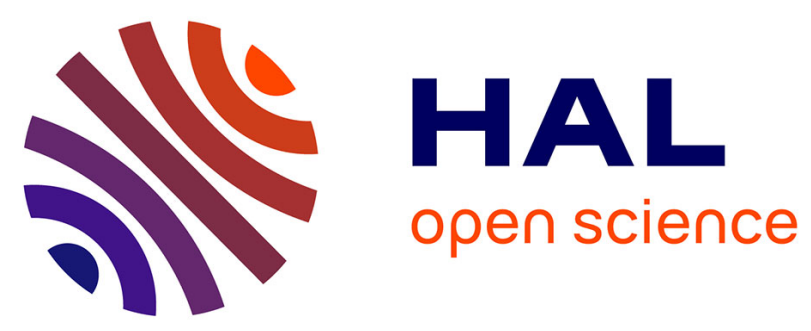

\title{
Mechanical characterization of a Low Density Sheet Molding Compound (LD-SMC): Multi-scale damage analysis and strain rate effect
}

Mohammadali Shirinbayan, Joseph Fitoussi, Navideh Abbasnezhad, Fodil

Meraghni, Benjamin Surowiec, Abbas Tcharkhtchi

\section{To cite this version:}

Mohammadali Shirinbayan, Joseph Fitoussi, Navideh Abbasnezhad, Fodil Meraghni, Benjamin Surowiec, et al.. Mechanical characterization of a Low Density Sheet Molding Compound (LD-SMC): Multi-scale damage analysis and strain rate effect. Composites Part B: Engineering, 2017, 131, pp.820. 10.1016/j.compositesb.2017.08.004 . hal-03269913

\section{HAL Id: hal-03269913 https://hal.science/hal-03269913}

Submitted on 24 Jun 2021

HAL is a multi-disciplinary open access archive for the deposit and dissemination of scientific research documents, whether they are published or not. The documents may come from teaching and research institutions in France or abroad, or from public or private research centers.
L'archive ouverte pluridisciplinaire HAL, est destinée au dépôt et à la diffusion de documents scientifiques de niveau recherche, publiés ou non, émanant des établissements d'enseignement et de recherche français ou étrangers, des laboratoires publics ou privés. 


\title{
Mechanical characterization of a Low Density Sheet Molding Compound (LD-SMC): Multi-scale damage analysis and strain rate effect
}

\author{
M. Shirinbayan ${ }^{\text {a, }}{ }^{*}$, J. Fitoussi $^{\text {a }}$, N. Abbasnezhad ${ }^{\text {a }}$, F. Meraghni ${ }^{\text {b }}$, B. Surowiec ${ }^{\text {c }}$, \\ A. Tcharkhtchi ${ }^{a}$ \\ a Arts et Métiers Paris Tech, PIMM - UMR CNRS 8006, 151 Boulevard de l'Hôpital, 75013 Paris, France \\ ${ }^{\mathrm{b}}$ Arts et Métiers Paris Tech, LEM3 - UMR CNRS 7239, 4 Rue Augustin Fresnel, 57078 Metz, France \\ c Plastic Omnium Auto Exterior, Sigmatech, Sainte Julie, France
}

Keywords:

Hollow glass microspheres

Low density SMC

Damage

Strain rate effect

\begin{abstract}
A B S T R A C T
This paper presents the results of an overall experimental characterization of the mechanical behavior of a Low Density Sheet Molding Compound (LD-SMC). LD-SMC is a polyester matrix containing mineral charge $\left(\mathrm{CaCO}_{3}\right)$ reinforced by discontinuous bundles of glass fibers and Hollow Glass Microspheres (HGM). After a description of its specific microstructure using several experimental methods (notably a new ultrasonic method), the overall mechanical response of two microstructure configurations (Randomly Oriented (RO) and Highly oriented (HO)) is analyzed at both macroscopic and microscopic scales in the case of tensile and compression tests. HGMs are homogeneously distributed into the overall volume of the material. At the microscopic scale, in-situ tensile tests inside a SEM and fracture surfaces observations allows analyzing the specific damage mechanisms occurring during tensile and compression loading performed in the mold flow direction ( $\left.\mathrm{HO}-\mathrm{O}^{\circ}\right)$ and perpendicularly to it $\left(\mathrm{HO}-90^{\circ}\right)$. A strong coupled influence of the presence of the HGM and fibers orientation has been emphasized. The results show that for $\mathrm{HO}-0^{\circ}$ configuration fiber-matrix debonding appears to be the predominant damage mechanism, whereas for $\mathrm{HO}-90^{\circ}$ configuration HGM-matrix debonding appears to be the predominant damage mechanism. High speed tensile tests are achieved using servo-hydraulic test equipment in order to study the strain rate effects (until $80 \mathrm{~s}^{-1}$ ) on mechanical macroscopic responses of HO- $0^{\circ}$, RO and HO$90^{\circ}$ samples. Strain rate has an obvious influence on the inelastic properties of LD-SMCs samples for all microstructures particularly on the damage threshold.
\end{abstract}

\section{Introduction}

According to the E. Commission [1], there is a trend to reduce weight in the transportation market. For example, by 2020, automakers should reduce carbon dioxide emission of their new cars by $30 \%$ compared to the admissible emission in 2011. On the other hand, several industrial reports [2] claim that using hollow glass microspheres can highly participate to the weight reduction.

\footnotetext{
* Corresponding author.

E-mail addresses: mohammadali.shirinbayan@ensam.eu (M. Shirinbayan), joseph.fitoussi@ensam.eu (J. Fitoussi), navideh.abbasnezhad@ensam.eu (N. Abbasnezhad), fodil.meraghni@ensam.eu (F. Meraghni), benjamin.surowiec@ plasticomnium.com (B. Surowiec), abbas.tcharkhtchi@ensam.eu (A. Tcharkhtchi).
}

Moreover, the use of low weight materials can also provide more precise molding, greater dimensional stability and improved resistance to heat distortion. From these points of view, weight reduction has become a major issue for automotive industry $[1,3,4]$.

Due to their high strength-to-weight ratio, SMC composites became a classical ideal choice for large structural automotive components $[5,6]$. Sheet molding compounds (SMCs) are fiberreinforced thermosetting semi-finished products processed by thermo-compression. Since the last two decades, SMC composite materials are successfully and widely used in automotive industry $[2,7]$. Consequently, a wide range of research was focused on the processing of SMC composites (material preparation, mold filling, curing, ejection and cooling) $[2,5,8,9]$. The first known SMC material development date back to the 1950s, but SMC compression 
molding analysis has been widely discussed only from the past decade [7,10-13]. Standard SMC products are manufactured in thin uncured and thickened sheets ranging from 1 to $4 \mathrm{~mm}$ thickness and usually consist of discontinuous fiber bundles, a mixture of thermosetting resin (polyester or vinylester and sometimes epoxy), fillers (calcium carbonate, alumina, etc.), and also additives (such as initiators, inhibitors, thickeners, etc.) [10-14]. Glass fiber has been mostly used for SMC materials reinforcement but carbon fiber SMC are recently developed especially for fatigue applications [2].

Classically, standard SMC materials have a wide range of advantages when compared to steel and other metal materials. For example, structural parts made from SMC can provide up to $30 \%$ lower weight compared to the corresponding steel parts. Moreover, standard SMCs are less expensive than metal sheets for low or middle volume productions since they need lower tool costs. Another important advantage for these non-corroding polymer composites concerns the more freedom design since smaller press radii can be used unlike steel and other metals. Furthermore, SMC composites are versatile materials and their formulation can be adjusted and tailored to meet the requirements of a diverse range of application $[3,4,6]$.

It is also meaningful to research low density SMC because of weight and cost reduction for industrial production. Oldenbo et al. [15] investigated a low density type of SMC (Flex-SMC) for automotive exterior body panels. This flex-SMC has a density almost $20 \%$ lower than standard SMC and provides higher impact resistance. Indeed, standard SMC and low density SMC develop different damage mechanisms. In standard SMC, Oldenbo et al. [15] show that damage initiation is due to debonding at the $\mathrm{CaCO}_{3}$ filler particle/matrix interface and leads to large matrix transverse cracks crossing the more miss-oriented fiber bundles. On the other hand, Jendli et al. show that fiber-matrix interface debonding is the predominant damage mechanism in standard SMC composites $[16,17]$. Comparatively, for low density SMC, damage initiates in transverse fiber bundles and extends to macro-scale transverse cracks [15].

On the other hand, the mechanical response of fiber reinforced polymeric composite materials varies significantly under different strain rates $[18,19]$. In the case of standard SMC, Jendli et al. [16] analyzed the damaged behavior of a standard SMC composite under dynamic loading. They showed that strain rate mainly governs the damage threshold and accumulation. They also introduced the notion of visco-damageable behavior leading to an increase of the ultimate strain and stress and owing to local effect of the strain rate at the fiber-matrix interface [16,17]. More recently, the viscodamage effect has been also demonstrated in the case of new vinylester based Advanced SMC composite presenting high fiber volume content $[20,21]$. It has been shown that increasing strain rate leads to a fiber-matrix damage threshold delay and lower damage accumulation kinetic. Moreover, these studies highlight that higher fiber content is causing a more intensive pseudodelamination phenomenon between bundles which appears to be enhanced by more oriented fibers in the tensile direction and by higher strain rate.

On the other hand, despite the great interest of using LD-SMCs to develop lighter vehicles, only few authors have studied the relations between microstructure and mechanical and damage behavior for this class of material. In particular, an investigation of the strain rate effect until $80 \mathrm{~s}^{-1}$ on the mechanical response and damage of these materials is missing in the literature (as well as it is known by the authors). This result is of first importance for crashworthiness optimization in the automotive industry.

In the present work, an experimental study is carried-out in order to widely investigate the mechanical behavior of a low density SMC provided by Plastic Omnium Auto Exterior. Special issues of this work concern strain rate and multi-scale damage effects on the overall behaviors of this material. Two kinds of LD-SMC specimen microstructures were prepared for physical, damage and mechanical characterizations: Randomly Oriented fibers (RO) and Highly Oriented fibers (HO). In the case of HO samples, two tensile directions were chosen in order to evaluate the anisotropic effect due to microstructure: HO- $0^{\circ}$ (parallel to the Mold Flow Direction (MFD)) and $\mathrm{HO}-90^{\circ}$ (perpendicular to the MFD). After physical and microstructure characterization, quasi-static tensile and compression tests have been performed for $\mathrm{RO}, \mathrm{HO}-90^{\circ}$ and $\mathrm{HO}-0^{\circ}$ specimens. Moreover, a multi-scale damage analysis has been performed in order to emphasize the effect of the presence of hollow glass microspheres. Strain rate effect has been investigated by performing high-speed tensile tests up to $80 \mathrm{~s}^{-1}$.

The main structure of this paper is as follows: firstly, density and microstructure ofLD-SMC was pointed out. Special attention was given to the comparing analysis of quasi-static compression and tensile tests. Besides, in-situ tensile tests performed inside a Scanning Electron Microscope and fracture surface analysis have been performed in order to emphasize the effect of microstructure and loading direction on the main damage and failure micromechanisms. An experimental study of the strain rate effect (from quasi-static to $80 \mathrm{~s}^{-1}$ ) on the overall tensile response of LDSMC is presented at the end of the paper. Finally, a multi-scale analysis of the damage effect for various microstructures, loading types and loading speeds is proposed in order to highlight the influence of the local damage mechanisms on the overall response of LD-SMCs.

\section{Material description and methods}

\subsection{Low Density Sheet Molding Compound (LD-SMC) composite}

Low Density Sheet Molding Compound (LD-SMC) composite is a type of SMC reinforced with chopped glass fibers bundles $(25 \mathrm{~mm}$ length) and hollow glass spheres. This pigmented SMC composite presents high mechanical properties and a good surface aspect. LDSMC compression molding is a complicated process. In the manufacturing process, raw materials on rolls should be cut to certain size and put into the mold under high temperature between $145{ }^{\circ} \mathrm{C}$ and $155^{\circ} \mathrm{C}$ and pressure between 80 and 120 bars. These conditions lead to decreasing of the viscosity of the materials and allow fulfilling the whole cavity of the mold. Then the materials stay in position with no reticulation for a short duration. The next step of the process consists of a reticulation time of the thermoset material that is the consolidation phase.

The composition of the studied LD-SMC is presented in Table 1. Two types of LD-SMC plates have been provided by Plastic Omnium Auto Exterior: Randomly Oriented (RO) and Highly Oriented (HO) plates. HO plates have been obtained by an initial charge put only in the left part of a rectangular mold $\left(30 \times 40 \mathrm{~cm}^{2}\right)$ before compression leading to material flow. RO plates were obtained without material flow by completely filling the mold.

Table 1

LD-SMC composition.

\begin{tabular}{ll}
\hline Product nature & Composition (content in mass percent) \\
\hline Glass fibers & $30 \%$ \\
Hollow glass spheres & $22 \%$ \\
Polyester resin & $12 \%$ \\
Filler & $32 \%$ \\
Other products & $4 \%$ \\
\hline
\end{tabular}




\subsection{Microstructure characterization methods}

\subsubsection{Microscopic observations}

Microscopic observations and image analysis, using Scanning Electronic Microscope (HITACHI 4800 SEM), have been performed in order to qualitatively investigate the material microstructure and especially fibers orientation.

\subsubsection{X-ray micro-tomography}

X-ray tomography allowed a three-dimensional visualization of LD-SMC. EasyTom nano setup, which comprises an X-Ray source, a rotating table and an X-ray detector, was used. The studied sample $\left(1 \times 1 \times 3 \mathrm{~cm}^{3}\right)$ was placed between the X-ray beam and the camera detector.

The principle of operation of the microstructure analysis by Xray micro-tomography is widely described in Ref. [22] (see Fig. 1).

\subsubsection{Ultrasonic measurement}

Ultrasonic waves have been recently used to characterize the orientation distribution of the fibers in an SMC composite [23]. In this paper, an original and simple ultrasonic measurement procedure is proposed in order to highlight the orientation distribution of the fiber bundles. The ultrasonic measurements were performed in immersion. The ultrasonic apparatus is composed of two probes, one transmitting (E) and other one receiving (R), separated by a known and constant distance $d$. The diameter of the probe is of $10 \mathrm{~mm}$. The sample is placed between the two probes with an angle of about $45^{\circ}$ versus the incident ultrasonic wave in order to create a shear wave which propagates inside the material in a direction determined by the Snell-Descarte law [24]. Consequently, the material is submitted to an ultrasonic shear stress in the plane defined by the incident wave (OL in Fig. 2) and the vector normal to the plane of the specimen ( $\vec{n}$ in Fig. 2). In Fig. 2, one can consider two limit cases:

a) Longitudinal orientation of the fibers,

b) Transverse orientation of the fibers.

In the case (a), the fibers are contained in the ultrasonic shear stress plane. This configuration corresponds to the maximum

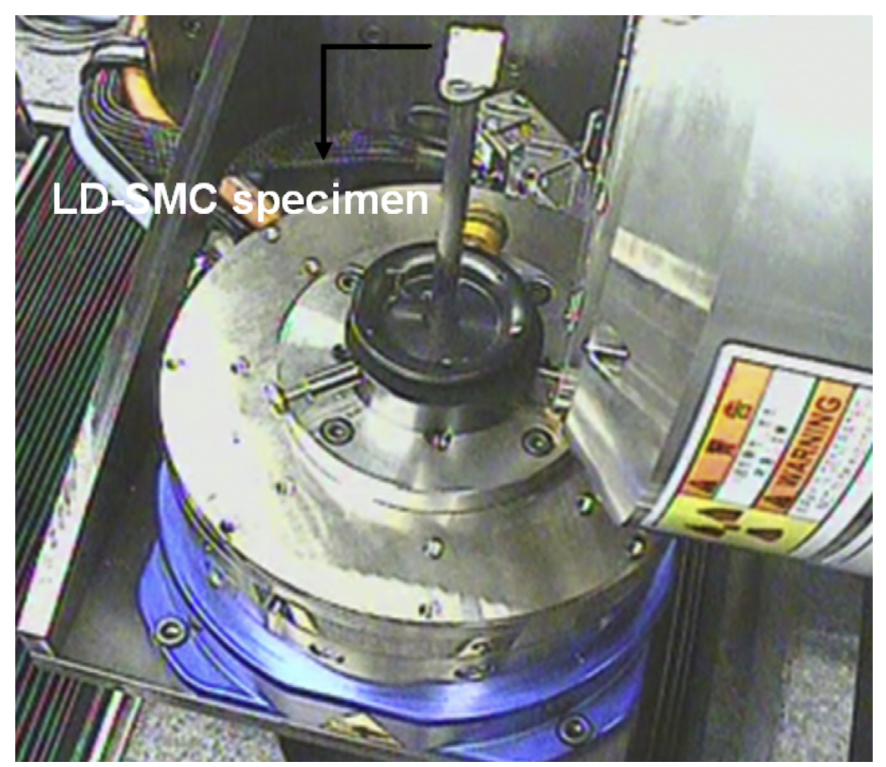

Fig. 1. Experimental setup of X-Ray micro-tomography (EasyTom nano).
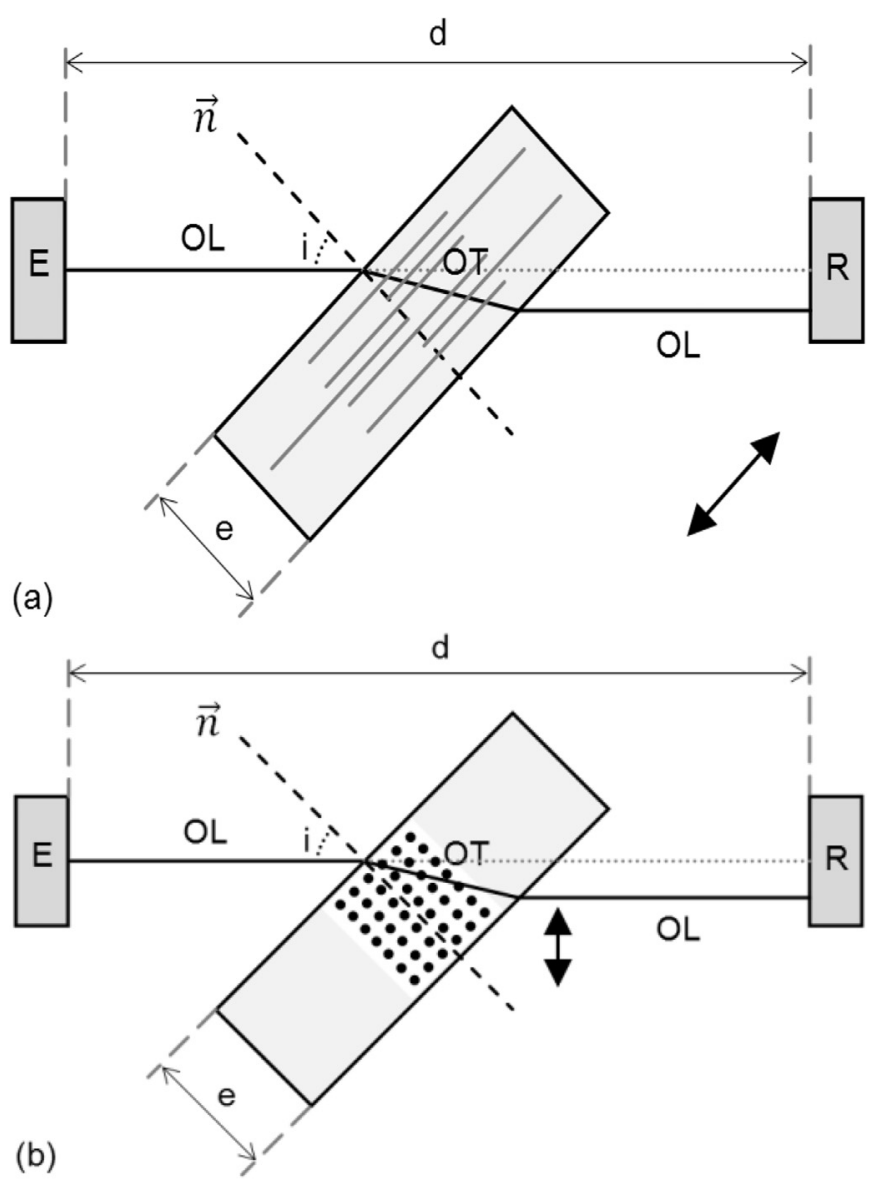

Fig. 2. Two limit cases fiber direction: (a) High $\mathrm{V}_{\mathrm{OT}}$ and (b) Low $\mathrm{V}_{\mathrm{OT}}$.

section of fiber submitted to the shear stress. Consequently, for longitudinally oriented fiber, the measured value of shear wave velocity, $\mathrm{V}_{\mathrm{T}}$, will be maximal. On the other hand, in the case of transversely oriented fibers (case (b)), fiber sheared section is reduced and leads to a minimal value of the shear wave velocity.

Thus, by rotating the sample around the axis $\vec{n}$ from $0^{\circ}$ to $360^{\circ}$, the value of $\mathrm{V}_{\mathrm{T}}$ varies as a function of the orientation distribution of the fibers. Fig. 3 shows an example of variation for a SMC specimen with strongly oriented in the $0^{\circ}$ direction. Thus, maximum $\mathrm{V}_{\mathrm{OT}}$

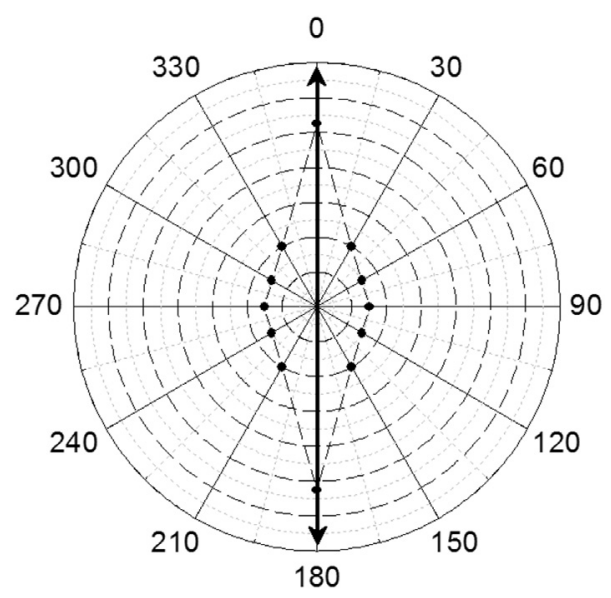

Fig. 3. Evolution of the shear wave velocity for a SMC composite with oriented fibers. 
values are found to be $0^{\circ}, 180^{\circ}$ and $360^{\circ}$.

For this sample, all the bundles of fibers are globally parallel to the plane of the SMC plate. Consequently, the $\mathrm{V}_{\mathrm{T}}$ curve appears to be symmetric. On the contrary, in the case of an out of plane fiber orientation, the evolution of $\mathrm{V}_{\mathrm{OT}}$ will be non symmetric. Indeed, out of plane oriented fibers are not in the same relative orientation versus the shear stress plane after a rotation of $180^{\circ}$ for example as illustrated in Fig. 4.

Ultrasonic measurements are a good and easy way to obtain a direct image of the distribution of orientation through the evolution of the shear wave velocity. This ultrasonic analysis was performed upon a volume that the surface was $60 \times 60 \mathrm{~mm}^{2}$ with thickness of $2.9 \mathrm{~mm}$ for both RO and HO samples.

\subsection{Mechanical characterization methods}

\subsubsection{Strain measurement}

For all types of tests, a contactless image analysis technique using a camera (high speed camera $[20,21]$ or classical camera) allows strain measurement by following the relative displacement of two marked points drawn on the surface of the specimen before testing.

\subsubsection{Quasi-static tension behavior and stiffness reduction}

Moreover, tensile tests until failure and loading-unloading tests at different increasing applied maximum stresses have been performed on MTS 830 hydraulic machine, in order to estimate tensile behavior and the macroscopic stiffness reduction during tension respectively. The specimen geometry used for quasi-static tensile test is the same as the optimized one for dynamic tensile tests (see section 2.3.5). The loading speed was $2 \mathrm{~mm} / \mathrm{min}$.

\subsubsection{Quasi-static compression tests}

Compression tests were achieved with the Instron 5881 testing machine with a loading cell of $50 \mathrm{kN}$, according to the standard NF ISO 6239. The loading speed was $2 \mathrm{~mm} / \mathrm{min}$. The LD-SMC specimen

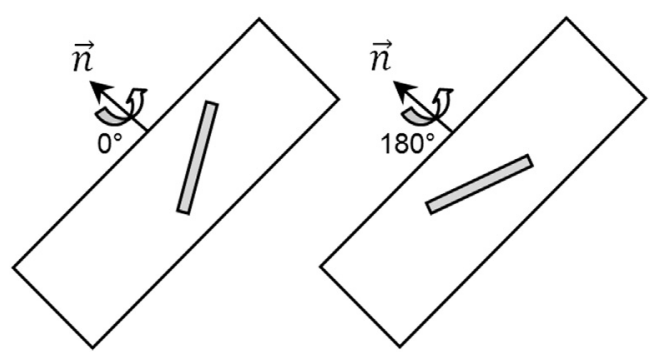

(a)

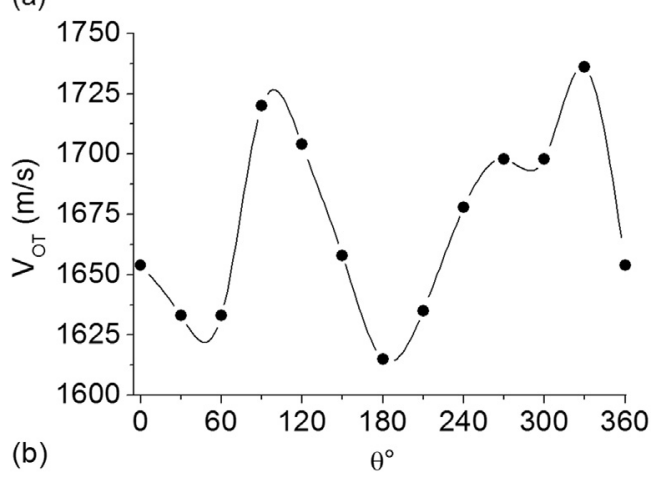

Fig. 4. (a) Effect of the sample rotation around $\vec{n}$ on the relative orientation on out plane fibers relative orientation, (b) Example of non symmetric curves obtained for out of plane fibers orientation, SMC sample. is positioned between two jaws as sketched in Fig. 5(a) and used specimen's geometry is shown in Fig. 5(b).

\subsubsection{Damage analysis using an in-situ tensile test device}

In situ observations were performed by subjecting the specimens into a quasi-static tension load $(0.5 \mathrm{~mm} / \mathrm{min})$ using a tensile micro-machine (Fig. 6), with a span length of $25 \mathrm{~mm}$, positioned inside a large SEM chamber (HITACHI 4800 SEM). To reduce the relaxation effect in the material, the observation time while maintaining the load was limited to $3 \mathrm{~min}$. The observation area corresponded to a polished thickness surface of the composite.

\subsubsection{High-speed tensile tests}

Using a servo-hydraulic test machine (Schenk Hydropuls VHS 5020) which is able to apply a crosshead speed range from quasistatic to $20 \mathrm{~m} / \mathrm{s}$, high strain rate tensile tests have been performed. An optimized damping joint consisting of a low impedance material - rubber nitrile ( $1.5 \mathrm{~mm}$ thickness) is placed between the slide and the hydraulic jack in order to attenuate partially the perturbation due to mechanical waves caused by inertial effects and the dynamic shock and also to limit the system ringing related to the hanging mass of the upper fixing system [16,17,20,21].

Furthermore, in order to reduce the perturbation wave's effect the same optimization procedure used in the previous works $[16,17,20,21]$ was followed. Therefore, the LD-SMC specimen geometry has been optimized as a result of numerical computations using ABAQUS finite element (FE) code (Fig. 7) in order to reach a homogeneous strain distribution and a rapidly stabilized strain rate within the specimen gauge section at the beginning of the loading stage. Finally the same specimen geometry used in a previous work $[20,21]$ ( 6 mm radius specimen) appears to be well adapted also for LD-SMC. It can be observed in the consecutive stress profiles that the shock wave vanishes very quickly and the stress distribution becomes rapidly relatively homogeneous (Fig. 8). Experimental strain evolutions confirm the efficiency of the chosen experimental conditions (see Fig. 9).

\section{Results and discussion}

\subsection{Specific density}

Hollow glass spheres allow reducing the density of sheet molding compound to $\sim 1.3 \mathrm{~g} / \mathrm{cm}^{3}$ compared to the conventional $\mathrm{SMC}$ of $1.85 \mathrm{~g} / \mathrm{cm}^{3}$ (i.e. a $30 \%$ reduction), while maintaining surface quality and mechanical performance. This combination allows the production of lighter parts [15].

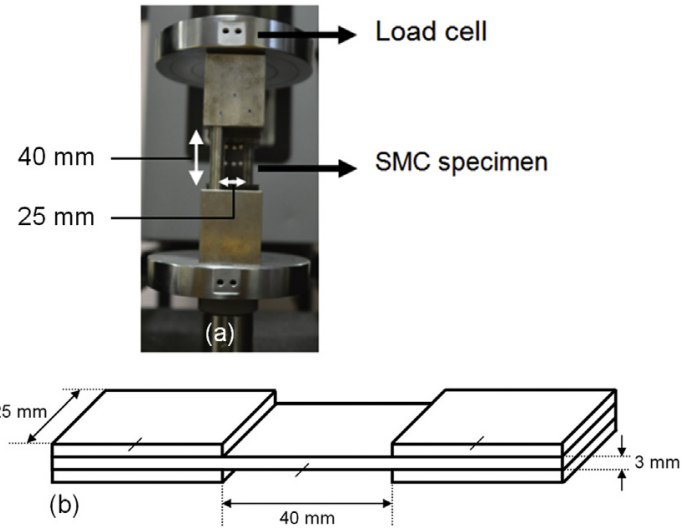

Fig. 5. (a) Experimental setup of compression test and (b) used specimen's geometry. 


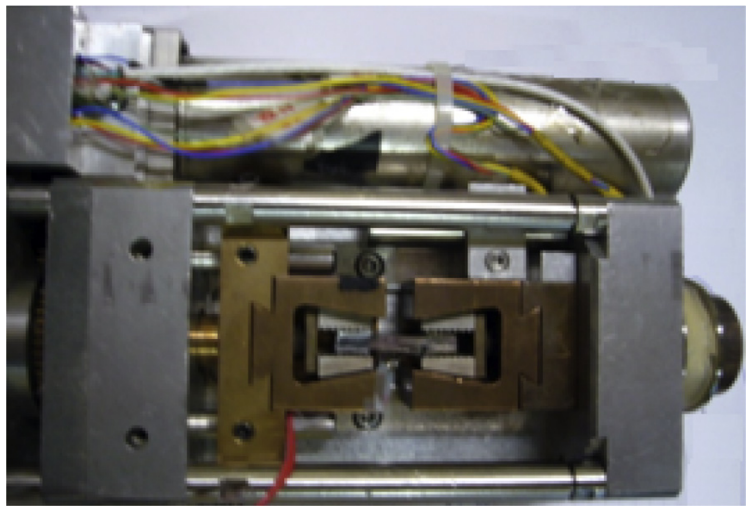

Fig. 6. The micro-machine tensile testing device. show more fibers oriented in the Mold Flow Direction (MFD) compared with randomly-oriented distribution of fibers (RO) [20].

One can note in Fig. 11 that the presence of hollow glass spheres generates out of plane glass fiber orientation during the flowing process. Thus, HO samples show more out of plane oriented bundles which is the inconvenience of using hollow glass spheres compare to standard SMCs which show more regular in-plane orientation.

\subsubsection{Microtomography $X$ analysis}

Fig. 12 exhibits the microstructures of LD-SMC RO and HO specimens of using X-ray micro-tomography. Actually, because of the difference of density between the constitutive phases of the composite, the later can be separated as it is shown in this figure. The global 3D spatial distribution of each phase can be analyzed

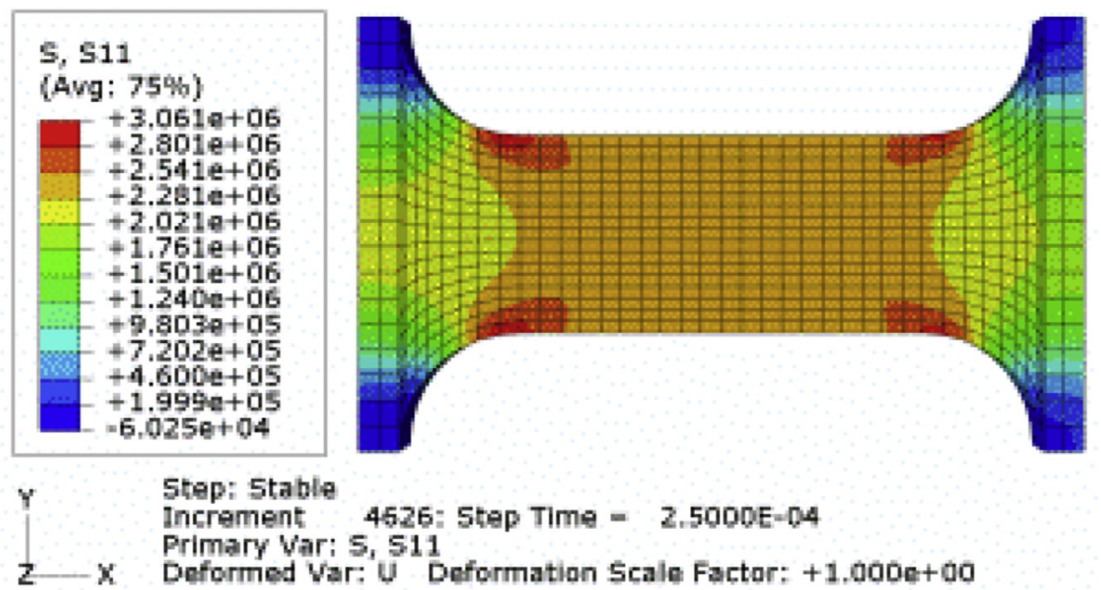

Fig. 7. FE computations optimizing the dumbbell-shaped specimen geometry parameters.

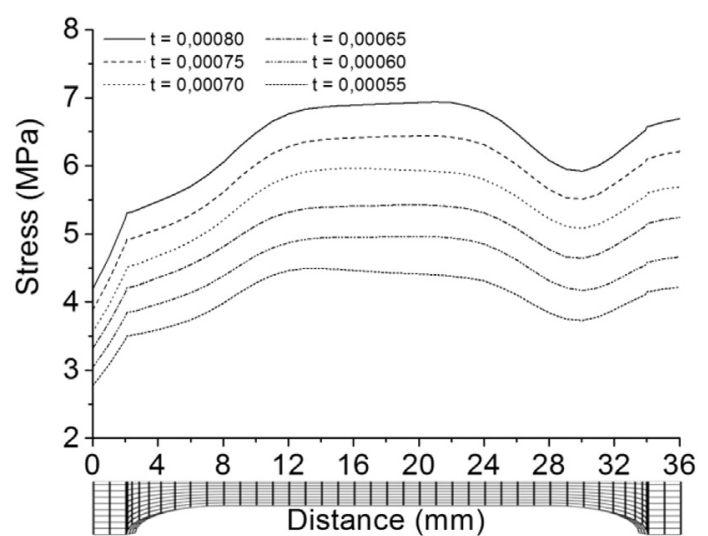

Fig. 8. Spatio-temporal profile of tensile stress calculated along the central line of the LD-SMC specimen. Loading conditions: imposed velocity $V=4 \mathrm{~m} / \mathrm{s}$.

\subsection{Microstructure analysis}

\subsubsection{SEM observation}

Fig. 10 shows clearly the orientation and distribution of fibers after cutting the plates in different directions (parallel or perpendicular to the Mold Flow Direction). One can note that there are two main differences in the following figures. According to the elliptic forms of the fibers appearing at the observation surface, $\mathrm{HO}$ sample

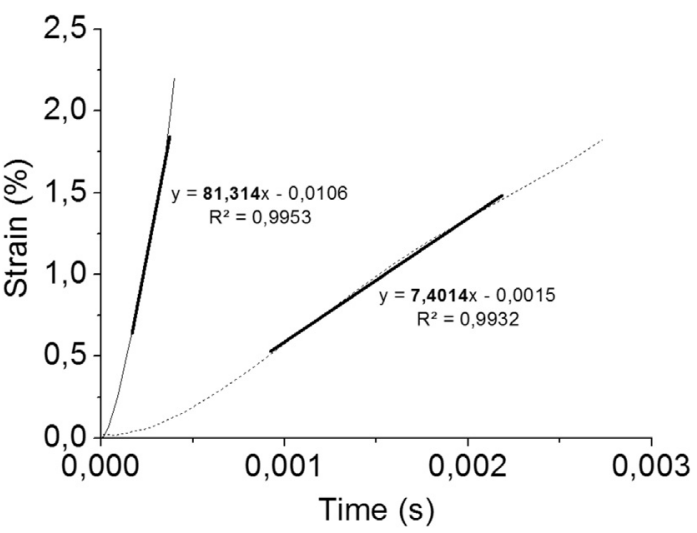

Fig. 9. Experimental strain evolutions at different high strain rates $\left(7.4 \mathrm{~s}^{-1}\right.$ and 81.3 $\left.\mathrm{s}^{-1}\right)$.

qualitatively.

One can notice that, for both HO and RO samples, the HGMs are homogeneously distributed over the whole volume of the composite. However, HGM content seems to decrease at the surfaces of the plate.

\subsubsection{Ultrasonic analysis}

Ultrasonic analysis obtained by the methodology introduced in paragraph 2.2.3 leads to typical results shown in Fig. 13. The 


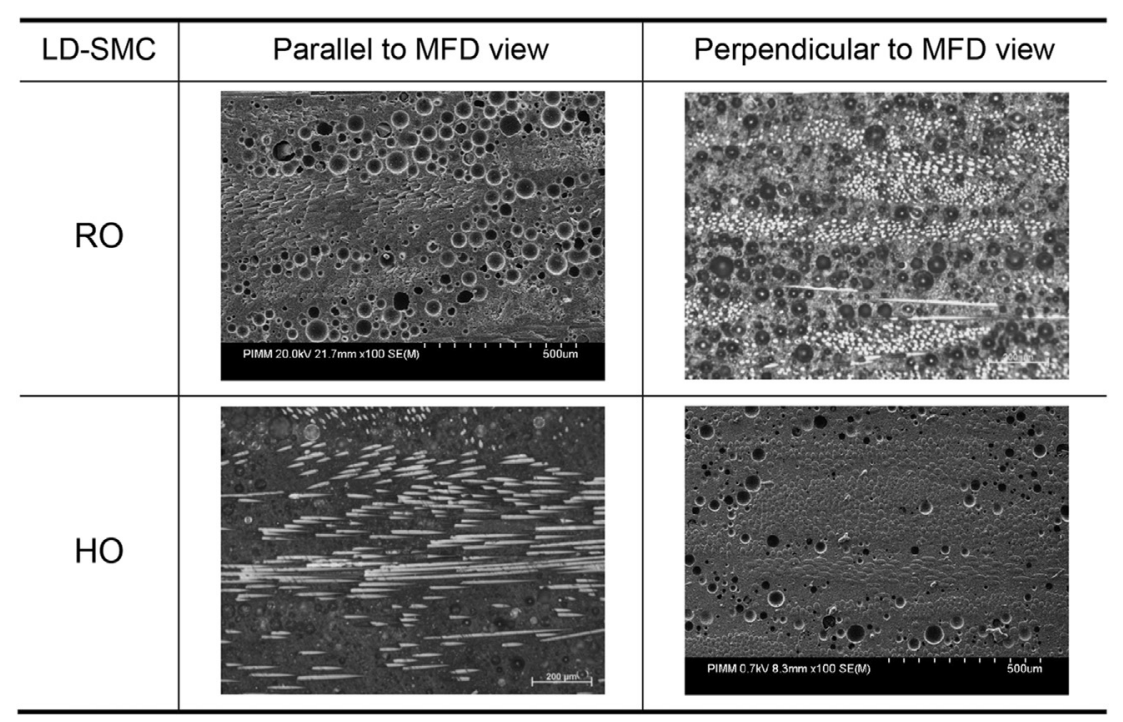

Fig. 10. Microstructure of LD-SMC: Bundle of fibers and hollow glass spheres.

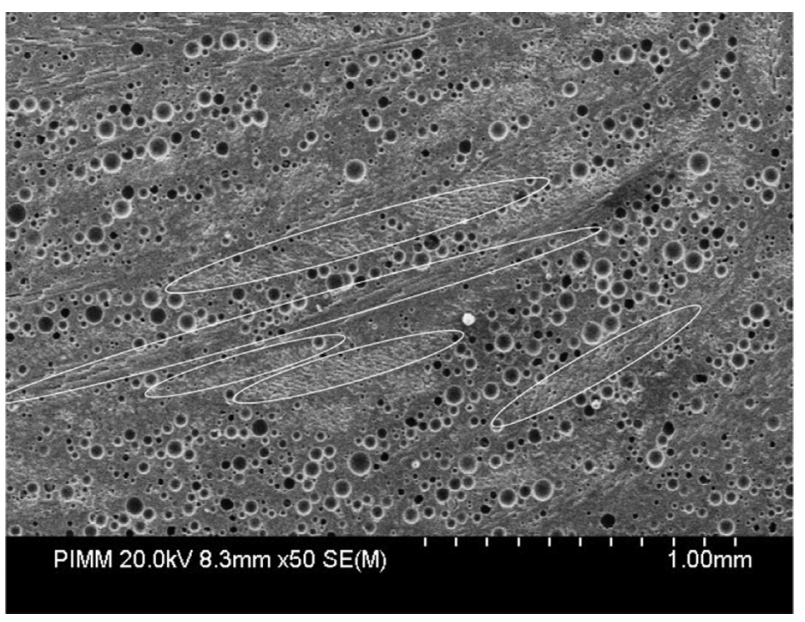

Fig. 11. Out of plane orientation of fiber bundles generated by the presence of hollow glass spheres (HO sample). evolutions of the shear wave velocity for HO SMC specimen (Fig. 13(a) and (b)) emphasize clearly fibers orientation in the mold flow direction $\left(0^{\circ}\right)$ since Fig. 13(c) shows a typical result obtained for a RO sample corresponding to a clearly transversely isotropic SMC microstructure.

The majority of samples (more than $80 \%$ ) of this plate present a main fibers orientation of $0^{\circ} \pm 30^{\circ}, 0^{\circ}$ corresponding to the mold flow direction during process. As mentioned above, the presence of hollow glass spheres forces out of plane glass fibers orientation and as a result the polar curves are not always symmetric (Fig. 13(b)). For randomly oriented plates (Fig. 13(c)), it can be observed that the polar diagrams of velocity are almost circular; which means that there are virtually no preferred direction reinforcements. As a whole, the plate appears rather as an isotropic material.

The propagation velocity of the ultrasonic waves is connected to microstructure and mechanical properties of the material. Coefficient $\mathrm{K}(\%)$, acoustical birefringence, is defined as:

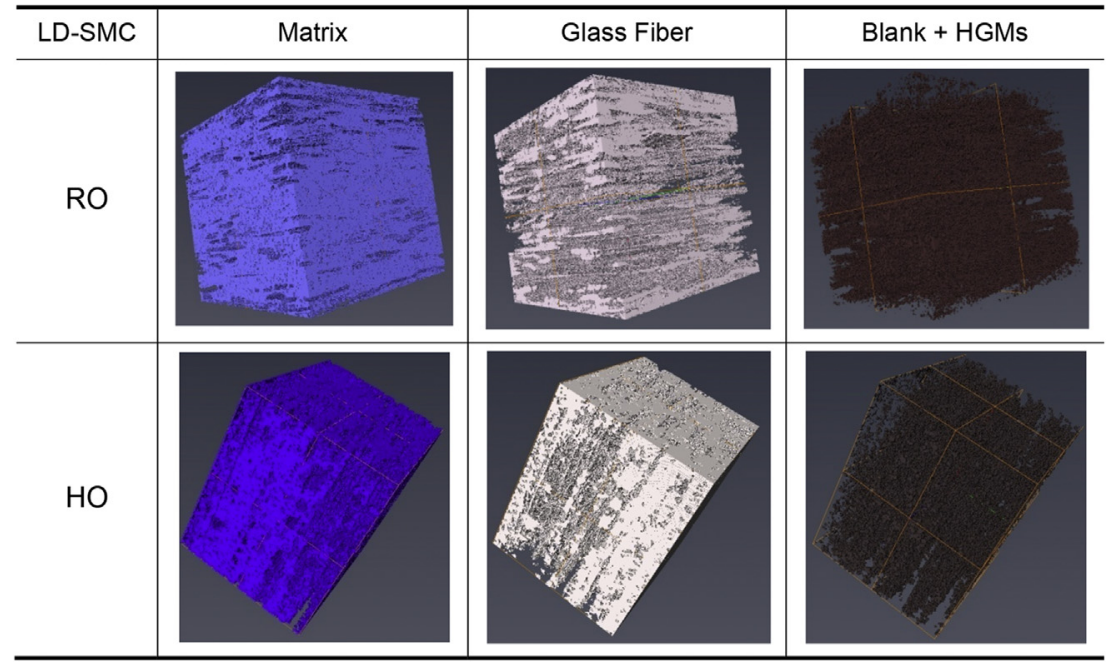

Fig. 12. Micro-tomography results. 


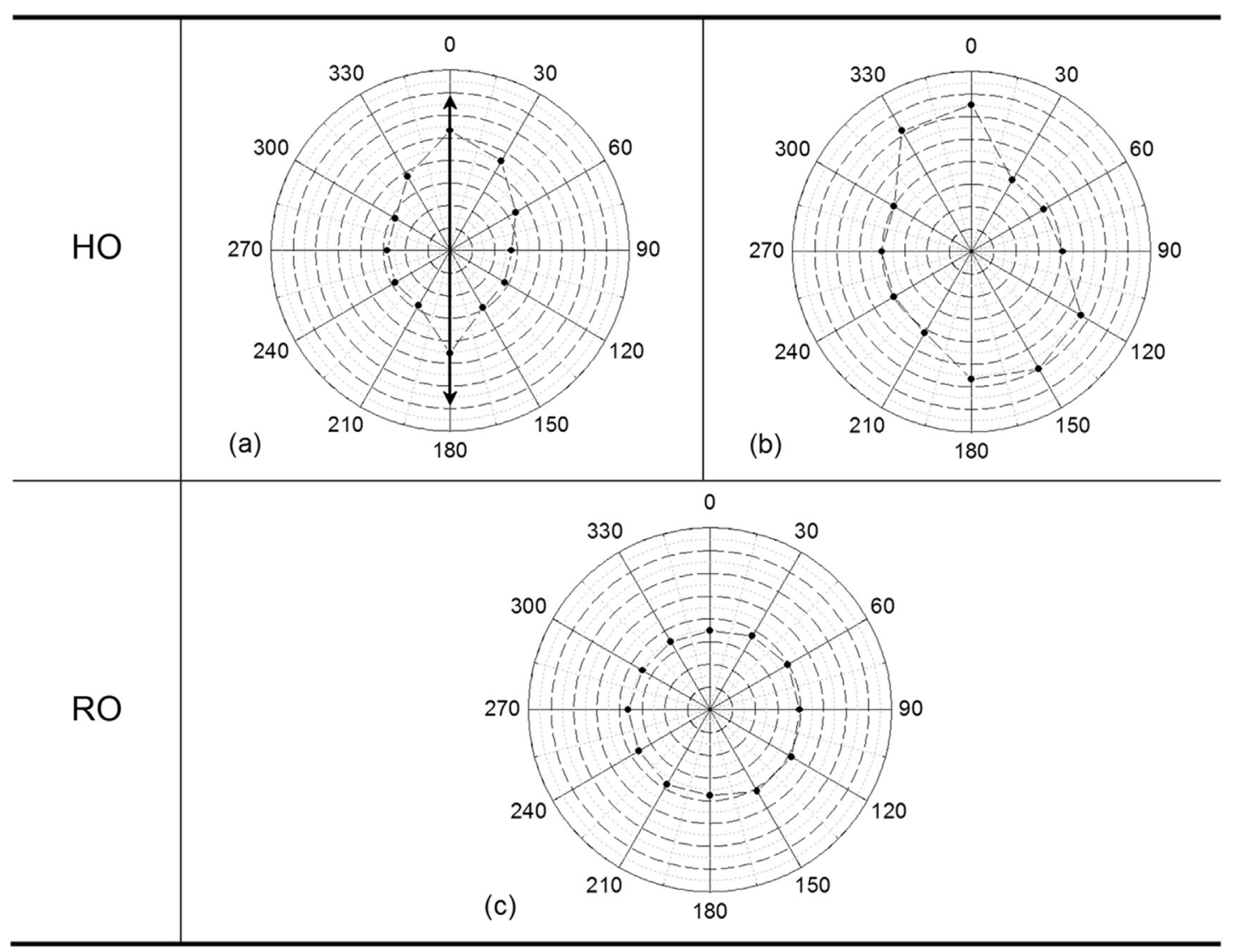

Fig. 13. Ultrasonic results; (a, b) HO plate and (c) RO plate.

$\mathrm{K}(\%)=\frac{\mathrm{V}_{\mathrm{OTmax}}-\mathrm{V}_{\mathrm{OTmin}}}{\mathrm{V}_{\text {OTavrage }}} \mathrm{x} 100$

Where $\mathrm{V}_{\mathrm{OT}}$ is the velocity of the shear waves for a given relative orientation $\theta$ of the composite (see Fig. 4). This coefficient characterizes orientation intensity and allows comparing different type of distribution of fibers orientation. Thus, a high value of acoustical birefringence coefficient " $\mathrm{K}$ " indicates a main direction of fibers.

Another issue of the ultrasonic measurements is the analysis of the spatial distribution of the fibers. Indeed, high values of density and tensile and shear waves velocities indicate the presence of a high quantity of fibers at the measurement location. The average values of $\mathrm{K}, \mathrm{V}_{\mathrm{OT}}$ and $\mathrm{V}_{\mathrm{OL}}$ for the 24 samples of two different $\mathrm{RO}$ plates and two different $\mathrm{HO}$ plates are presented in Table 2.

\subsection{Quasi-static mechanical behavior}

\subsubsection{Overall tension and compression behavior}

Tension and compression tests results are superposed in Fig. 14 for both configurations. Five similar tests have been performed for each configuration. The representative curves are presented in a

Table 2

The average values of $\mathrm{K}, \mathrm{V}_{\mathrm{OT}}$ and $\mathrm{V}_{\mathrm{OL}}$ after ultrasonic measurement.

\begin{tabular}{lll}
\hline Parameter & RO samples & HO samples \\
\hline $\mathrm{K}(\%)$ & 3.3 & 11 \\
$\rho\left(\mathrm{g} / \mathrm{cm}^{3}\right)$ & 1430 & 1460 \\
$\mathrm{~V}_{\mathrm{OT}}(\mathrm{m} / \mathrm{s})$ & 1420 & 1570 \\
$\mathrm{~V}_{\mathrm{OL}}(\mathrm{m} / \mathrm{s})$ & 2100 & 2700 \\
\hline
\end{tabular}

normalized form relative to the tensile RO curve taken as a reference. For both configurations, no significant difference is observed on the linear part of the curves between tension and compression leading to similar Young's modulus.

In these curves, the strong effect of the fiber orientation discussed in section 3.2 is clearly emphasized in terms of modulus and inelastic behavior until failure. One can note that both of tension and compression tests, for each kind of specimen, have similar Young's modulus in the firstly linear period. Moreover, except for the RO samples, tension and compression behavior appears to be similar until failure. On the other hand, compression curve of RO configuration presents a longer linear elastic stage followed by a plateau which will be discussed after.

Another specific behavior can be observed in the $\mathrm{HO}-90^{\circ}$ curves. After a maximum value of $0.45 \sigma_{\mathrm{r}(\mathrm{RO})}$ the stress progressively decreases until a very low stress level near to $0,1 \sigma_{\mathrm{r}(\mathrm{RO})}$. This phenomenon has been observed for about $25 \%$ of the tested specimens and will be discussed in section 3.4. The other specimens have been broken for the maximum stress $\left(0.45 \sigma_{\mathrm{r}(\mathrm{RO})}\right)$ as it is illustrated in Fig. 14(b).

\subsubsection{Effect of fiber orientation}

Fig. 15(a) shows a comparison between the quasi static tensile tests results obtained on $\mathrm{HO}-0^{\circ}, \mathrm{RO}$ and $\mathrm{HO}-90^{\circ}$ samples at room temperature. Note that in the case of $\mathrm{HO}-90^{\circ}$ the curve has been stopped just before the stress decreases described in the previous section. As it can be seen, the value of Young's modulus of $\mathrm{HO}-0^{\circ}$ is about $12 \mathrm{GPa}$ which is higher than those of RO (10 GPa) and HO-90 ( $9 \mathrm{GPa}$ ) samples. The failure stress also highly depends on the fibers orientation. One can note that failure stress of $\mathrm{HO}-0^{\circ}$ is about four times higher than that of $\mathrm{HO}-90^{\circ}$ samples. 

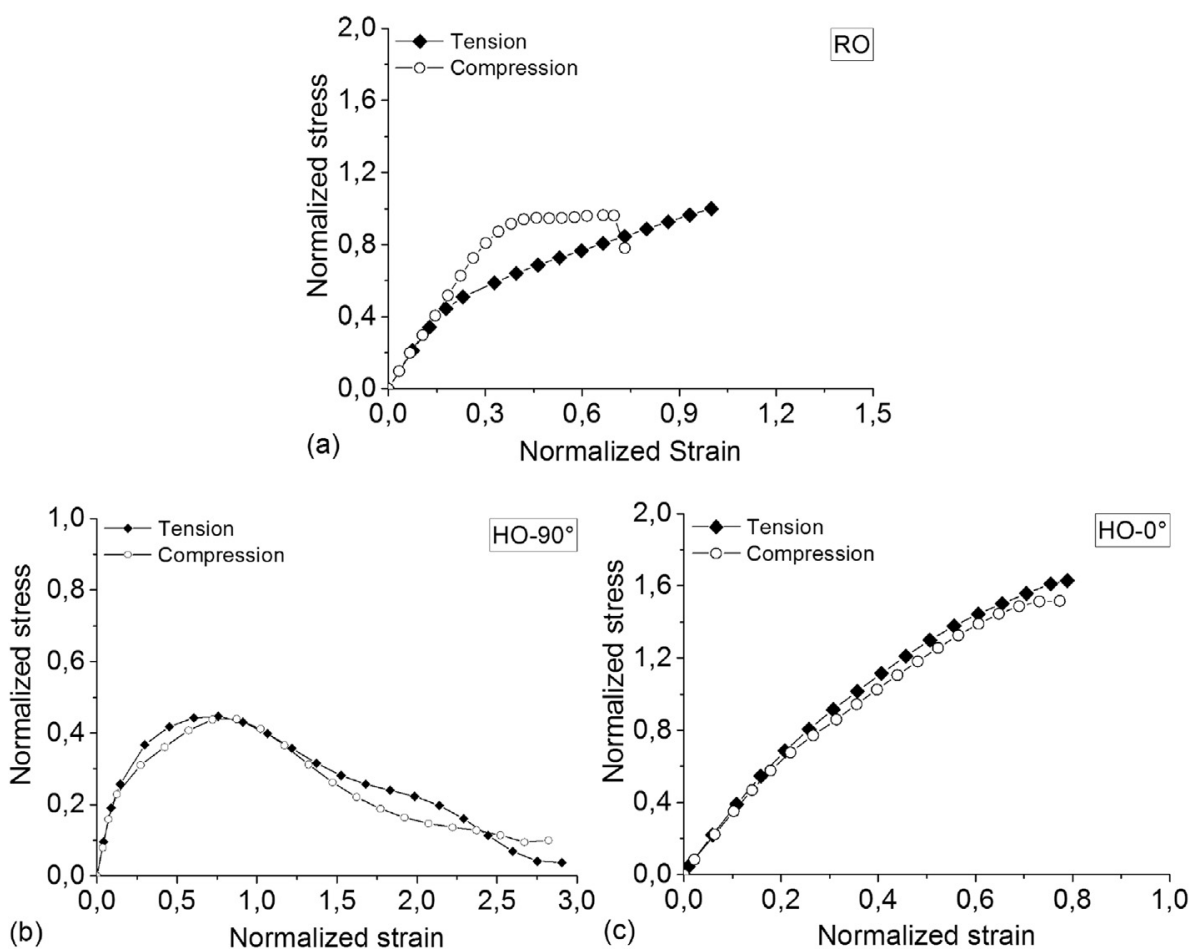

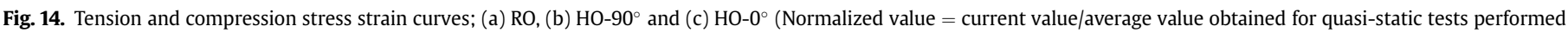
on RO-LD-SMC).
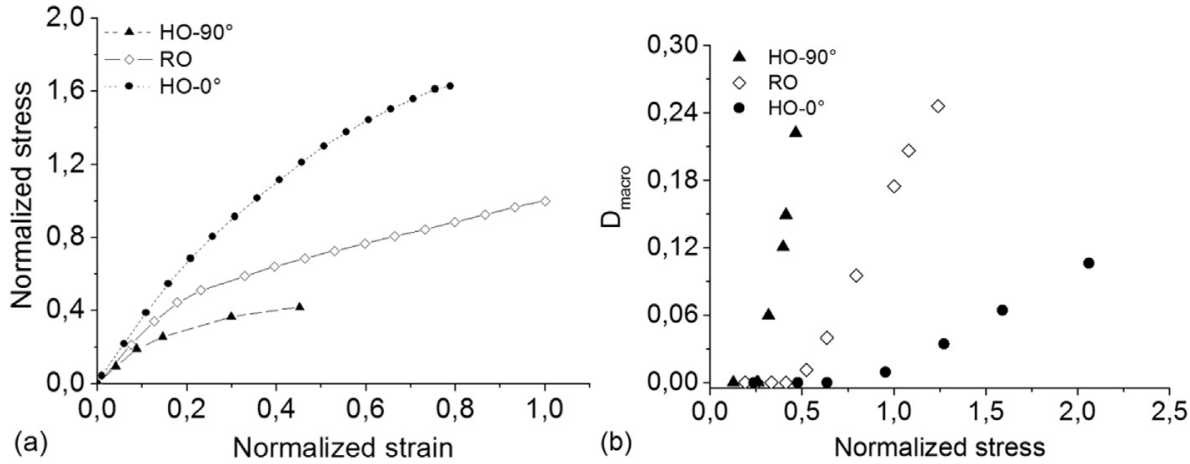

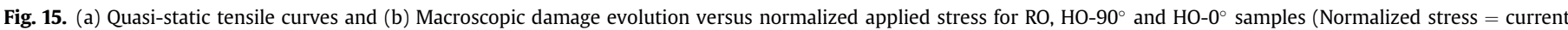
value/average value obtained for quasi-static tests performed on RO-LD-SMC)

In order to emphasize the damage development effect, threshold and kinetic of damage can be characterized by the evolution of the well-known scalar damage parameter $[25,26]$ which is defined as:

$\mathrm{D}_{\text {macro }}=1-\mathrm{E}_{\mathrm{D}} / \mathrm{E}_{0}$

Where $E_{0}$ and $E_{D}$ are the Young's modulus of the virgin and damaged material respectively. The residual Young's modulus after damage, $E_{D}$, is measured by a "loading-unloading" procedure in which reached the value of stress increases at each reloading stage. Then, the evolution of the macroscopic damage parameter can be measured and plotted against the stress level for the three kinds of specimen: $\mathrm{HO}-0^{\circ}, \mathrm{RO}, \mathrm{HO}-90^{\circ}$ in accordance to their quasi-static tensile curves [21] (Fig. 15(b)).

One can note that $\mathrm{HO}-0^{\circ}$ has the lowest damage parameter evolution. For example, in the case of $\mathrm{HO}-0^{\circ}$ samples, macroscopic damage begins at a stress level of0.75 $\sigma_{\mathrm{r}(\mathrm{RO})}$, significantly higher than those of $\mathrm{HO}-90^{\circ}$ and RO samples (corresponding to $0.25 \sigma_{\mathrm{r}(\mathrm{RO}) \text {, }}$ $0.50 \sigma_{\mathrm{r}(\mathrm{RO})}$, respectively). Moreover, $\mathrm{HO}-0^{\circ}$ damage parameter only grows up until 0.11 for a sharply increasing stress up to $2.10 \sigma_{\mathrm{r}(\mathrm{RO})}$ while this value for $\mathrm{HO}-90^{\circ}$ strongly increases up to 0.22 for a corresponding stress slightly near to $0.50 \sigma_{\mathrm{r}(\mathrm{RO})}$. Moreover, one can note that damage threshold and kinetic are directly correlated to orientation: Increasing fiber orientation in the load direction leads to higher damage threshold and lower kinetic of damage propagation.

\subsection{Damage mechanism analysis}

In section 3.3, the overall mechanical behavior of the LD-SMC in this study has been analyzed at the macroscopic scale. Specific effects have been emphasized. In this section, a damage analysis is performed at the microscopic scale in the case of tensile and 

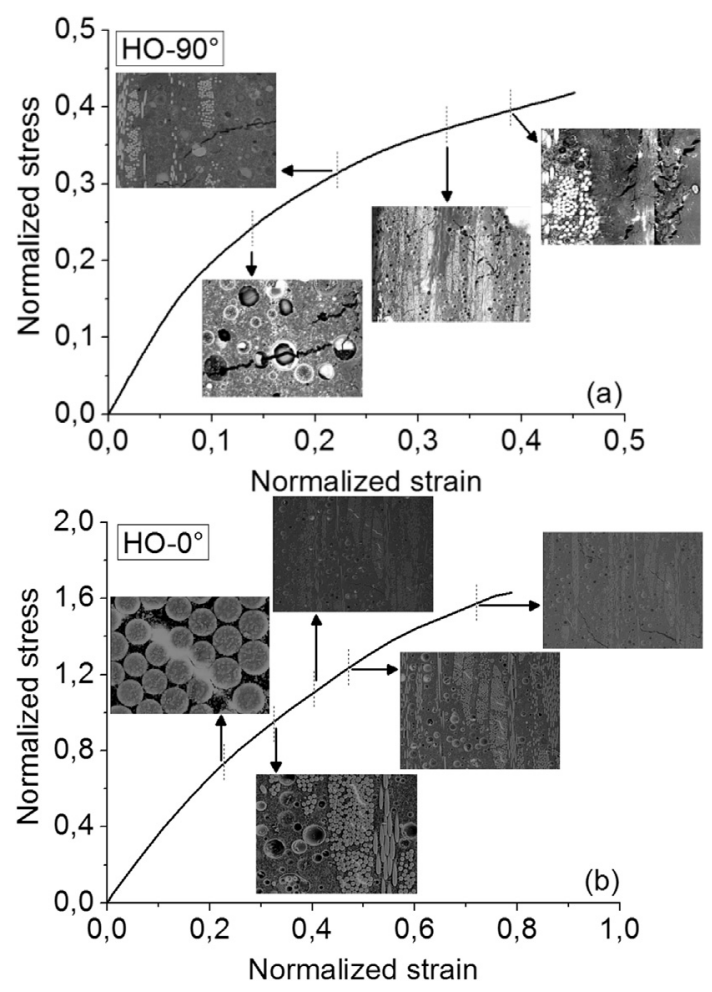

Fig. 16. Experimental in-situ quasi-static tensile tests coupled to microstructure observations for $\mathrm{HO}-90^{\circ}$ and $\mathrm{HO}-0^{\circ}$ samples.

compression tests. Microscopic observations are correlated to macroscopic behavior described above in order to determine the specific role played by the presence of HGMs in damage development.

\subsubsection{Tensile tests}

3.4.1.1. In situ SEM tensile tests. In-situ quasi-static tensile tests have been performed inside the chamber of a SEM as described in section 2.3.4 in order to observe the evolution of damage development at the microstructure scale. HO microstructure has been investigated for two tensile directions: $\mathrm{HO}-90^{\circ}$ and $\mathrm{HO}-0^{\circ}$. The same representative observation zone was microscopically analyzed at consecutive increasing values of applied stress level: about $3 \times 5 \mathrm{~mm}^{2}$. Preliminary tests showed that this investigation zone is large enough to be qualitatively representative of the damage mechanisms occurring during the tensile loading. Thus, the local investigation presented here can be assumed to be qualitatively representative of the damage accumulation during LD-SMC tensile loading.

In the case of $\mathrm{HO}-90^{\circ}$ samples (see Fig. 16), the first observed damage phenomenon appears together with the first non-linearity of the tensile curve and corresponds to failure or debonding of the HGMs occurring in the fiber depleted zones. This leads to the propagation of micro-cracks perpendicularly to the tensile direction. For a higher value of applied stress, this damage mechanism is spreading through the whole observation zone in a diffuse manner on several HGMs locations. At the same time, the early existing micro-cracks continue growing. By increasing applied stress, fibermatrix interface failure begins appearing on different bundle locations, especially on the more disoriented fibers versus the loading direction. Furthermore, one can observe coalescence of the two types of micro-cracks which grow simultaneously at higher applied stress values. Finally, when reaching the maximum stress, local shear deformation around the bundles leads to the pseudodelamination of the bundles near to failure.

The failure stage described above concerns about $75 \%$ of the tested specimens for which failure occurs at the maximum stress. However, as mentioned above, for an amount of $25 \%$ of $\mathrm{HO}-90^{\circ}$ specimens, the stress value decreases gradually from the maximum stress until a lower stress level near to zero. In order to investigate this phenomenon, some tests have been interrupted during the decreasing stage in order to observe the evolution of the microstructure. Fig. 17 shows clearly a progressive propagation of transverse micro-cracks caused by debonding of HGMs followed by propagation through the polyester matrix. Hence, when most fibers are oriented at $90^{\circ}$ versus the loading direction, matrix is submitted to high stress values in such a way that the diffuse development of this kind of micro-cracks is favored. Moreover, these micro-cracks can easily propagate through $90^{\circ}$ oriented bundles (Fig. 17(b)) and can be sometimes deviated or hindered by the presence of a fibers bundle less disoriented. Consequently, for an appropriate distribution of fiber orientation $\left(\mathrm{HO}-90^{\circ}\right)$, a progressive "unbuttoning" phenomenon of the HGMs coupled to fiber-matrix interface debonding leads to a wide networks of transverse micro-fractures of the matrix and is accompanied by an overall progressive increase of the strain together with a decrease of the stress as in Fig. 14(b). Note that this phenomenon does not occur for microstructures presenting more dispersed distributions of fibers orientations for which the presence of more oriented bundles participates to a more equilibrated local stress distribution between the different phases (matrix and reinforcements). One can also notify that the stress decrease is less frequent in the case of compression tests (only $5 \%$ of the $\mathrm{HO}-90^{\circ}$ tested specimen). Indeed, transverse micro-cracking diffusion is not favored by compression loading.

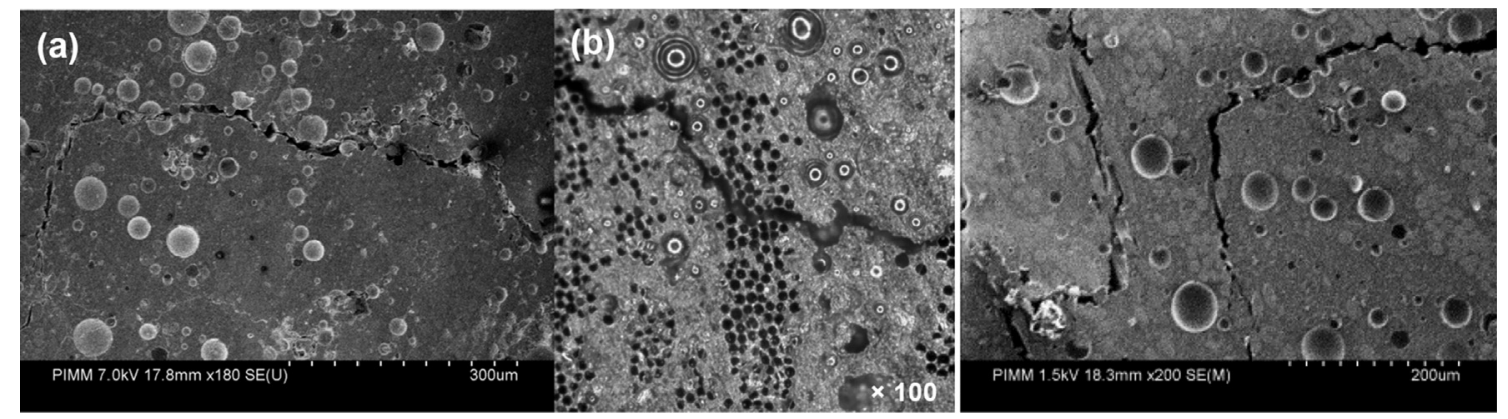

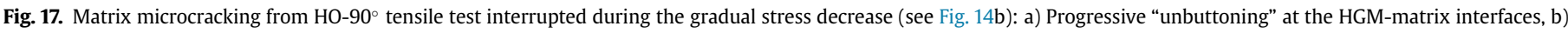
Easy propagation through $90^{\circ}$ oriented bundle, c) Deviation of matrix micro-cracks by more disoriented bundles. 
Finally, we must also indicate that this phenomenon has never been observed for high strain rate tensile tests described in section 3.5. Indeed, the HGMs "unbuttoning" phenomenon described above corresponds to a stable propagation on the micro-cracks which is more difficult to obtain at high strain rates.

On the other hand, damage development observed during a tensile test performed on $\mathrm{HO}-0^{\circ}$ samples is similar to that observed in standard SMC [16,17]. For this configuration, damage is mostly governed by debonding of fiber-matrix interfaces which still appears at less than $30 \%$ of the failure stress in a diffuse manner and preferentially in the more disoriented fibers. Indeed, as a result of the $0^{\circ}$ predominant fiber orientation, the load is distributed more homogeneously between bundles and matrix. Thus, apart from fiber-matrix interface failure described above, no other significant damage mechanism has been noticed until $1.60 \sigma_{\mathrm{r}(\mathrm{RO})}$ (just before failure) for which value of matrix breakage appears in the predominant matrix areas. These observations showed that no evident correlation between matrix failure and HGM presence has been pointed out.

3.4.1.2. Fracture surface observations. Post-mortem SEM observations of fracture surfaces have also been used to investigate the role played by HGMs in the final stage of failure (Fig. 18). It can be emphasized that, for all studied fiber direction configurations,
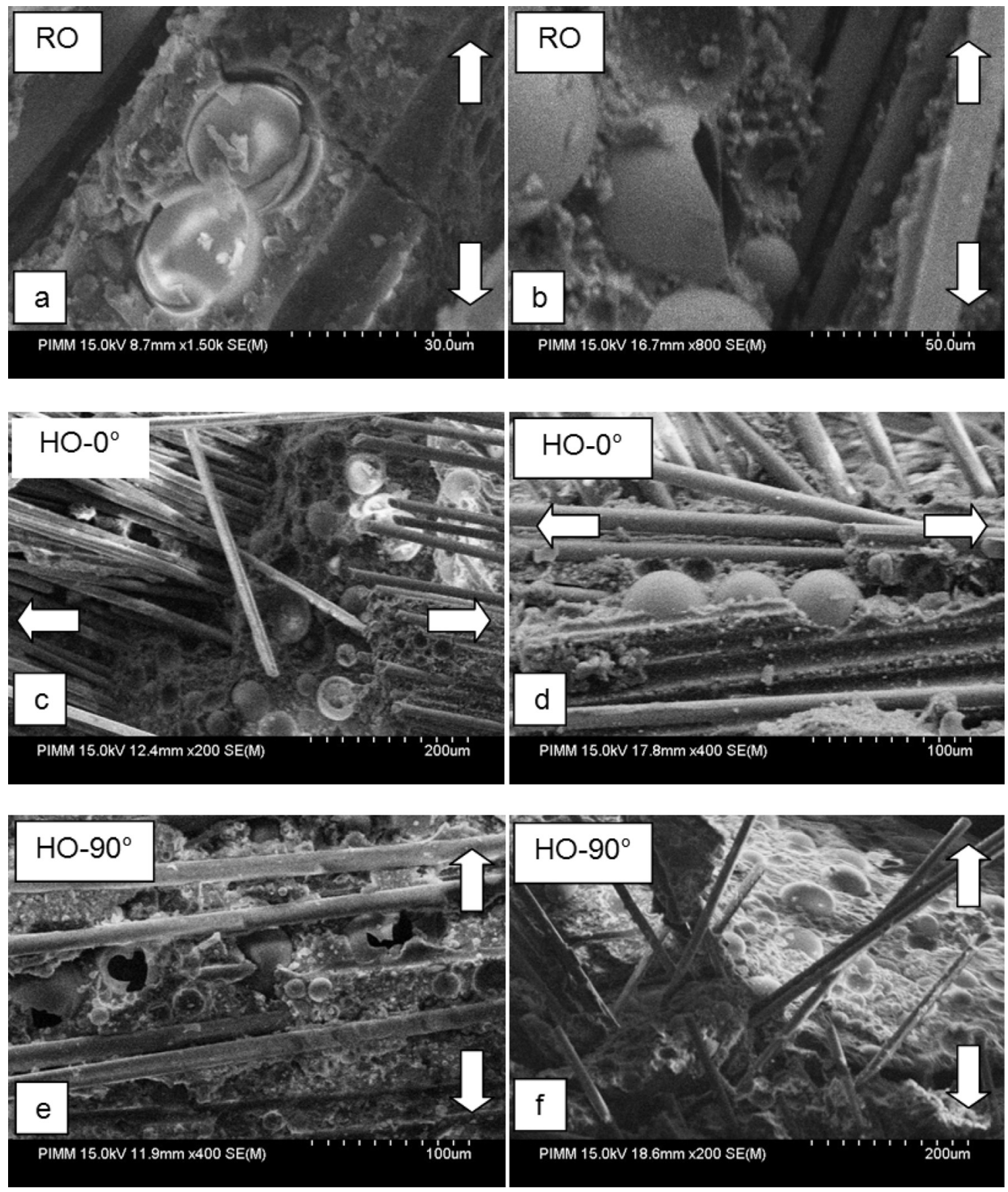

Fig. 18. SEM micrograph of failure surface after quasi-static tensile test. 


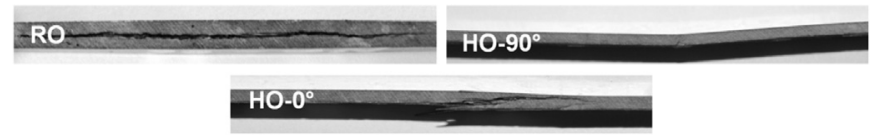

Fig. 19. Macroscopic observation of failure surface after compression test.

HGMs presence is involved in the final failure. Indeed, SEM micrographs highlight both debonding and breakage of the HGMs which always appears in the fracture surfaces together with debonded fiber-matrix interfaces ( $a, b, d$ and e). Micro-cracks propagation into the matrix between fibers and fiber bundles and HGMs always precedes final failure ( $c$ and $\mathrm{f}$ ). Moreover, observation of the HO- $0^{\circ}$ fracture surfaces showed that the presence of HGMs around the more disoriented bundles of fibers promotes the failure process in these areas (d). On the other hand, when they are located around $0^{\circ}$ oriented fibers, failure process brings about matrix failure through HGMs interface failure which fosters pull-out of the neighboring bundles of fibers (c). All these observations are in good accordance with the in-situ tensile test results, shown in Fig. 16.

This microstructural damage analysis leads to the general conclusion that damage development and failure during tensile tests performed on LD-SMC is strongly dependent of the interaction between fiber orientation and HGMs presence.

\subsubsection{Compression tests}

3.4.2.1. Macroscopic observation. One can notice in Fig. 14(a), that in the case of RO samples, damage threshold under compression is more than two times higher than in the case of tensile loading. However, especially for this configuration, the stress-strain curve exhibits a plateau stage which is related to a delamination phenomenon shown in Fig. 19 at macroscopic scale. On the other hand,
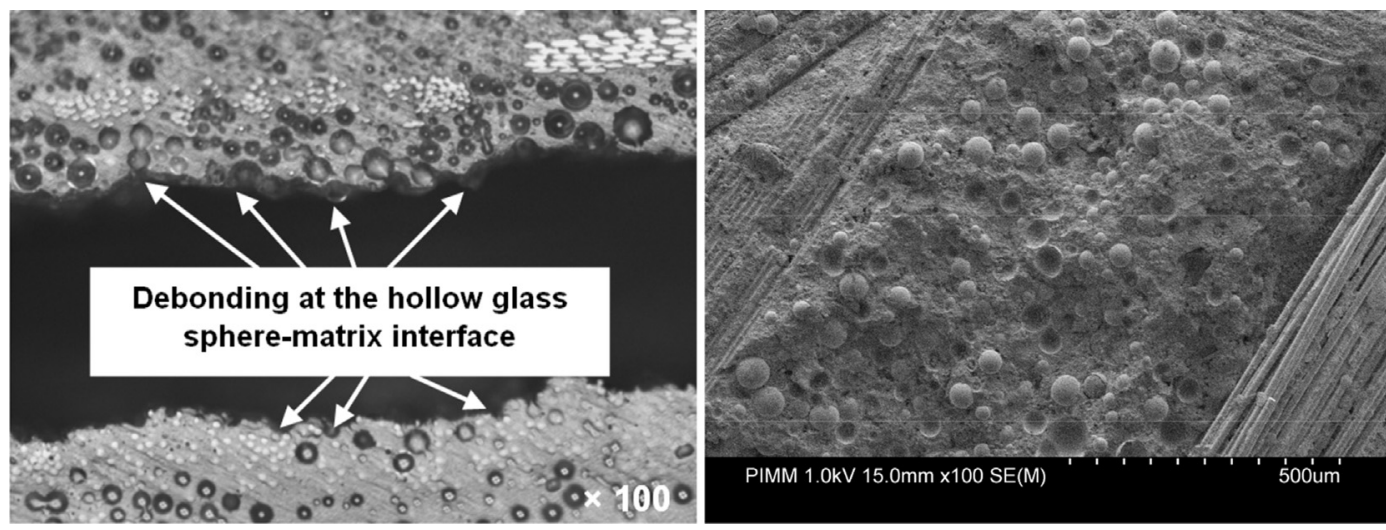

Fig. 20. Microscopic observation of failure surface after compression test of RO sample.
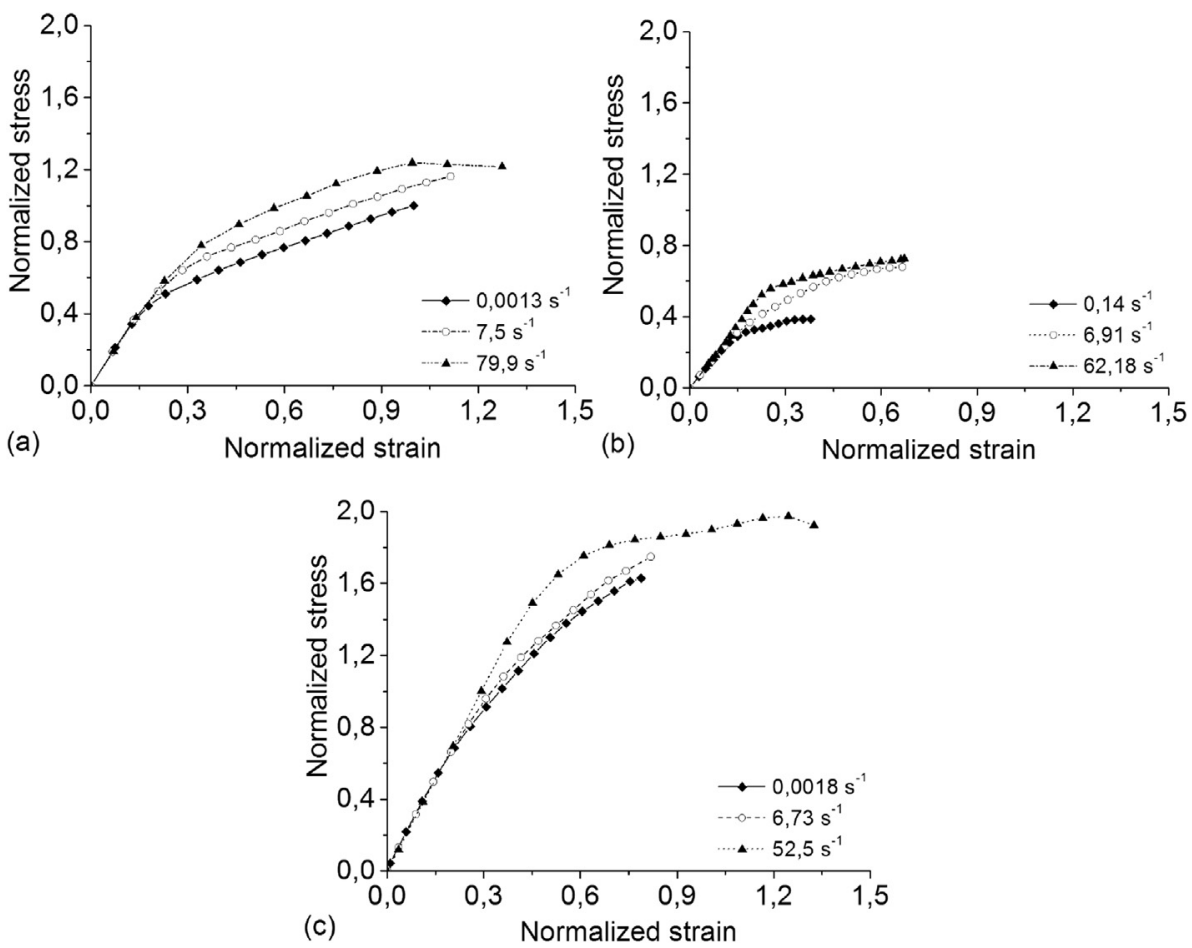

Fig. 21. Experimental high strain rate tensile curves: (a) RO, (b) $\mathrm{HO}-90^{\circ}$ and (c) $\mathrm{HO}-0^{\circ}$ (Normalized value $=$ current value/average value obtained for quasi-static tests performed on RO-LD-SMC). 


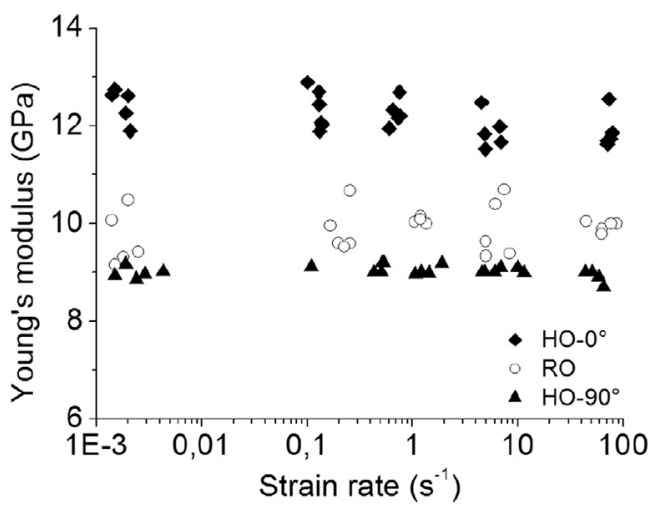

Fig. 22. Evolution of the Young's modulus vs. Strain rate.

one can note that compression tests performed on $\mathrm{HO}-0^{\circ}$ samples lead to wide pseudo-delamination between fiber bundles while HO- $90^{\circ}$ breakage remains much localized without significant delamination.

3.4.2.2. Fracture surface observations. Microscopic observation of RO sample after compression test (Fig. 20) confirms that a macroscopic delamination occurs consecutively to debonding at the hollow glass spheres-matrix interfaces. This appears clearly to be the predominant failure mechanism which is probably due to a higher content of HGM between two LD-SMC sheets during elaboration.

However, this phenomenon is not observed for HO microstructure. Indeed, in the case of $\mathrm{HO}-0^{\circ}$ and $\mathrm{HO}-90^{\circ}$, compression load is distributed more homogeneously between fiber bundles and matrix. Then, after each damage event, local stresses are redistributed in other locations. Consequently, damage mechanisms propagate in a diffuse manner similarly to those observed under tensile loading.

\subsection{Effects of strain-rate and microstructure on the overall tensile response}

LD-SMC automotive structures are frequently submitted to crash events. Thus, in order to complete the overall characterization of LD-SMC mechanical behavior proposed in this paper, a study of the strain rate effect is needed. Following the procedure described in section 2.3.5, stress-strain $(\sigma-\varepsilon)$ tensile tests curves are plotted for increasing strain rates up to $80 \mathrm{~s}^{-1}$ for RO and HO samples. Typical curves are shown in Fig. 21. One can clearly note that the overall behaviors of LD-SMCs is highly load-rate dependent. However, although there are some slight fluctuations due to microstructure dispersion, no significant evolution of the young's modulus is observed (Fig. 22). The elastic behavior can be considered to be insensitive to strain rate in the studied strain rate range. Then, independently one can consider that average values of Young's moduli are 10, 9 and $12 \mathrm{GPa}$ for $\mathrm{RO}, \mathrm{HO}-90^{\circ}$ and $\mathrm{HO}-$ $0^{\circ}$ samples, respectively, independently of the strain rate.

Moreover, the evolution of other mechanical characteristics versus strain rate has been estimated. Namely, stress and strain damage thresholds ( $\sigma_{\text {threshold, }} \varepsilon$ threshold $)$ and stress and strain ultimate values ( $\sigma_{\text {ultimate, }} \varepsilon_{\text {ultimate }}$.

Strain rate effect on LD-SMC brings about a strong damage onset delay. In fact, damage thresholds (Fig. 23(a) and (b)) strongly increase with strain rate for the three kinds of samples. For example, one can note an increase of threshold stress average values from QS to $80 \mathrm{~s}^{-1}$, of $120 \%, 130 \%$ and $114 \%$ for $\mathrm{HO}-0^{\circ}$, R0 and $\mathrm{HO}-90^{\circ}$ samples respectively. Comparatively, failure characteristics are less influenced by strain rate for which moderate increase of ultimate stress average values are observed: 33\%, 58\% and 55\% respectively. On the
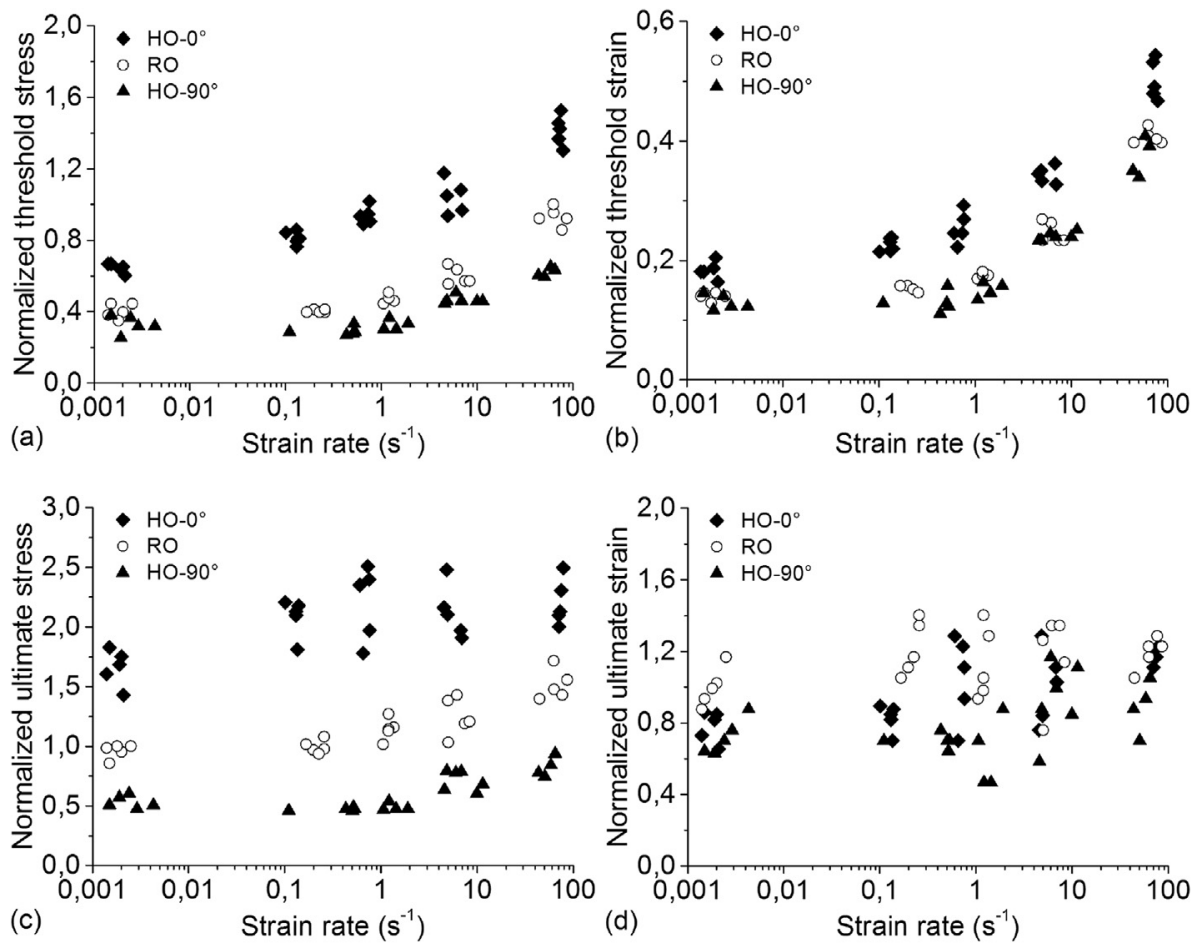

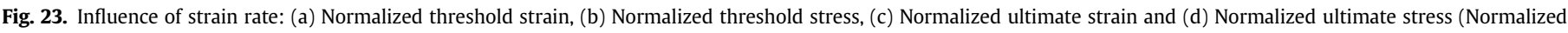
value $=$ current value/average value obtained for quasi-static tests performed on RO-LD-SMC). 
other hand, observations of fracture surfaces of specimens broken at high loading rate did not reveal significant differences compared to those broken at low or quasi-static rates. Indeed, when increasing strain rate, damage mechanisms initiation and propagation such as debonding at the fiber-matrix or HGM-matrix interfaces might be delayed. A general conclusion of this part of the study is that, similar to SMCs [16,17] and A-SMCs [20,21], high strain rate effect on LD-SMCs brings about the viscous nature of the damage at the local scale and leads to an apparent viscodamageable behavior at the macroscopic scale.

\section{Conclusion}

A multi-scale experimental analysis of the influence of HGMs in LD-SMC microstructure has been performed. A general conclusion to be drawn from this work is that the introduction of HGM strongly influences damage development and failure of LD-SMC. Three microstructure configurations of LD-SMCs (RO, HO- $90^{\circ}$ and $\mathrm{HO}-0^{\circ}$ ) were prepared and submitted to tension and compression loading. In order to emphasize the coupled effect of HGMs presence and fiber orientation distribution, damage mechanisms development has been investigated at the microscopic scale. Finally, an evaluation of the strain rate effect concludes this study.

The main conclusions of this work may be specified in various areas as follows:

- HGMs are homogeneously distributed into the overall volume of the material. They are mainly localized around the glass fiber bundles and in the fiber depleted zones.

- Fiber orientation distribution strongly influences the mechanical response of $\mathrm{LD}-\mathrm{SMC}$.

- No significant asymmetry has been observed between tensile and compression curves for $\mathrm{HO}$ configuration, although compression damage threshold is deleted during compression loading of RO specimens.

- Despite some scattering due to microstructure variations, the elastic modulus is insensitive to strain rate. Strain rate has an obvious influence on the inelastic properties of LD-SMCs samples for all microstructures particularly on the damage threshold (first non-linearity).

- When the fibers are mostly oriented in the loading direction (HO- $0^{\circ}$ configuration) fiber-matrix debonding appears to be the predominant damage mechanism, when the fibers are mostly oriented perpendicularly to the loading direction (HO-90 configuration), HGM-matrix debonding appears to be the predominant damage mechanism.

- Final failure is always affected by the presence of the HGMs more or less coupled to the fiber-matrix interface debonding depending on the fiber orientation distribution: the more the fibers are oriented perpendicularly to the loading direction, the more HGM debonding drives the final failure.

- Concentration of HGMs between two SMC sheets after processing leads to a macroscopic delamination in compression,

- One may conclude that there is a coupled effect of the viscous nature of HGMs-matrix and fiber-matrix interfaces which leads to a strong influence of the strain rate on the macroscopic behavior of LD-SMCs.

\section{References}

[1] E. Commission. Further $\mathrm{CO}_{2}$ emission reduction from cars and vans: a win-win for the climate, consumers, innovation and jobs. 2012. Brussels.

[2] Palmer J, Savage L, Ghita OR, Evans KE. Sheet moulding compound (SMC) from carbon fiber recyclate. Compos Part A Appl Sci Manuf 2010;41(9):1232-7.

[3] Kraemer A, Lin S, Brabandt D, Böhlke T, Lanza G. Quality control in the production process of SMC lightweight material. Procedia CIRP 2014;17:772-7.

[4] Fette M, Sander P, Wulfsberg J, Zierk H, Herrmann A, Stoess N, et al. Molds manufactured by selective laser melting for the production of thermoset fiber reinforced plastic aircraft components. Procedia CIRP 2015;35:25-30.

[5] Huang B, Zhao L. Bridging and toughening of short fibers in SMC and parametric optimum. Compos Part B Eng 2012;43(8):3146-52.

[6] Asadi A, Miller M, Singh AV, Moon RJ, Kalaitzidou K. Lightweight sheet molding compound (SMC) composites containing cellulose nanocrystals. Compos Struct 2017;160:211-9.

[7] Asadi A, Baaij F, Mainka H, Rademacher M, Thompson J, Kalaitzidou K. Basalt fibers as a sustainable and cost-effective alternative to glass fibers in sheet molding compound (SMC). Compos Part B Eng 2017;123:210-8. Available online 9 May 2017.

[8] Odenberger PT, Andersson HM, Lundström TS. Experimental flow-front visualisation in compression moulding of SMC. Compos Part A Appl Sci Manuf 2004;35(10):1125-34.

[9] Kim MS, Lee WI, Han WS, Vautrin A, Park CH. Thickness optimization of composite plates by Box's complex method considering the process and material parameters in compression molding of SMC. Compos Part A Appl Sci Manuf 2009;40(8):1192-8.

[10] Dumont P, Orgéas L, Favier D, Pizette P, Venet C. Compression moulding of SMC: in situ experiments, modelling and simulation. Compos Part A Appl Sci Manuf 2007;38:353-68.

[11] Kim MS, Lee WI, Han WS, Vautrin A. Optimization of location and dimension of SMC pre-charge in compression molding process. Comput Struct 2011;89(15-16):1523-34.

[12] Kim D-K, Choi H-Y, Kim N. Experimental investigation and numerical simulation of SMC in compression molding. J Mater Process Technol 1995;49(3-4): $333-44$.

[13] Park CH, Lee WI, Yoo YE, Kim EG. A study on fiber orientation in the compression molding of fiber reinforced polymer composite material. J Mater Process Technol 2001;111(1-3):233-9.

[14] Grabalosa J, Ferrer I, Zúñiga A, Ciurana J. Influence of processing conditions on manufacturing polyamide parts by ultrasonic molding. Mater Des 2016;98: 20-30.

[15] Oldenbo M, Fernberg SP, Berglund LA. Mechanical behaviour of SMC composites with toughening and low density additives. Compos Part A Appl Sci Manuf 2003;34(9):875-85.

[16] Jendli Z, Meraghni F, Fitoussi J, Baptiste D. Micromechanical analysis of strain rate effect on damage evolution in sheet molding compound composites. Compos Part A Appl Sci Manuf 2004;35(7-8):779-85.

[17] Jendli Z, Fitoussi J, Meraghni F, Baptiste D. Anisotropic strain rate effects on the fibre-matrix interface decohesion in sheet moulding compound composites. Compos Sci Technol 2005;65(3-4):387-93.

[18] Fereshteh-Saniee F, Majzoobi GH, Bahrami M. An experimental study on the behavior of glass-epoxy composite at low strain rates. J Mater Process Technol 2005;162-163:39-45.

[19] Gurusideswar S, Velmurugan R, Gupta NK. High strain rate sensitivity of epoxy/clay nanocomposites using non-contact strain measurement. Polymer 2016;86:197-207.

[20] Shirinbayan M, Fitoussi J, Meraghni F, Surowiec B, Bocquet M, Tcharkhtchi A. High strain rate visco-damageable behavior of Advanced Sheet Molding Compound (A-SMC) under tension. Compos Part B Eng 2015;82:30-41.

[21] Shirinbayan M, Fitoussi J, Bocquet M, Meraghni F, Surowiec B, Tcharkhtchi A. Multi-scale experimental investigation of the viscous nature of damage in Advanced Sheet Molding Compound (A-SMC) submitted to high strain rates. Compos Part B Eng 2017; 115:3-13.

[22] ID19 ESRF. <http://www.esrf.eu/UsersAndScience/Experiments/Imaging/ ID19>.

[23] Schladitz K, Büter A, Godehardt M, Wirjadi O, Fleckenstein J, Gerster T, et al Non-destructive characterization of fiber orientation in reinforced SMC as input for simulation based design. Compos Struct 2017;160:195-203.

[24] Dupertuis MA, Proctor M, Acklin B. Generalization of complex snell-descartes and fresnel laws. J Opt Soc Am A 1994;11(3):1159-66.

[25] Krajcinovic D, Mastilovic S. Some fundamental issues of damage mechanics. Mech Mater 1995;21(3):217-30.

[26] Krajcinovic D. Selection of damage parameter - art or science. Mech Mater $1998 ; 28(1-4): 165-79$. 